\title{
RevistAleph
}

\section{AO MEU AMADO MESTRE: PROFESSOR DOUTOR JORGE NAJJAR}

\author{
Leonardo Dias da Fonseca ${ }^{84}$
}

Peço licença aos leitores, pois nesta merecida homenagem ao professor pesquisador, ao intelectual e ativista da educação pública, professor Doutor Jorge Nassim Vieira Najjar, eu não poderia deixar de compartilhar alguns momentos íntimos em que tive a honra e o prazer de conviver e aprender com ele.

Seu passamento tão prematuro deixa um grande vácuo no campo progressista, nos espaços de defesa da educação pública. Professor Jorge Najjar era atuante incansável em fóruns, conselhos, congressos, na gestão de associações acadêmicocientíficas e na participação em inúmeros eventos das redes municipais do estado do Rio de Janeiro em que era convidado a participar. Sempre estava com a agenda cheia e disputada, mas nunca recusava um convite, fazia de tudo para conseguir conciliar com seus outros compromissos.

Pude acompanhá-lo em vários desses eventos em que era recebido quase que como uma celebridade por ex-alunos e ex-orientandos, concursados nas redes em que ele era convidado a palestrar ou para ministrar cursos. Para ele sempre foi um prazer enorme estar nestes espaços. Pois tinha um forte compromisso com a escola pública que o formou, da educação básica à pós-graduação, trajetória esta que foi ressaltada em seu memorial na banca de progressão para professor titular da Faculdade de Educação da Universidade Federal Fluminense (FEUFF).

Foi nesta banca, ocorrida no dia 19/08/2020, a última vez em que pude interagir com ele, mesmo que de forma virtual, sinal dos tempos de pandemia. Jorge já estava bem debilitado por conta de sua doença, defendeu seu memorial com o rigor acadêmico e a ternura que lhes eram característicos. Foi um evento com muita emoção, cheia de amorosidade e homenagens por tanto que ele fez pela educação. Eu, em

\footnotetext{
84 Doutorando em Educação do Programa de Pós-Graduação da UERJ (ProPEd-UERJ). Graduado em Pedagogia e Mestre em Educação pela UFF. Professor Assistente do colegiado de pedagogia do Centro de Estudos Superiores de Tefé, Universidade do Estado do Amazonas.
} 


\section{RevistAleph}

particular, bastante emocionado, agradeci o privilégio de ter tido cerca de doze anos de convivência e aprendizagem ao seu lado.

Jorge tinha um coração enorme, de uma generosidade que emociona. O conheci durante a graduação, ele já ocupava o cargo de vice-diretor da faculdade de educação da UFF, em 2007, e eu estava como presidente do Diretório Acadêmico Anísio Teixeira e representava os alunos no Colegiado de Unidade da faculdade. Por vezes fui muito ácido e crítico a sua gestão, que tinha como diretora a professora Márcia Pessanha. Mas, ele nunca perdia a ternura, mesmo quando muitos dos integrantes se posicionavam de forma dura contra a gestão.

No ano de 2009, quando terminou minha bolsa de iniciação científica, mandei um e-mail para alguns professores perguntando se estava por ocorrer alguma seleção para contratação de bolsista, pois eu não podia ficar sem um auxílio, tendo em vista que meus pais moravam no interior e as bolsas ajudavam a me manter em Niterói. Jorge foi um dos que me respondeu, sinalizando o processo de seleção para um projeto que ele iria coordenar. Foi a partir deste ano e da minha aprovação na seleção que nossa convivência se tornou mais intensa.

Anos mais tarde, ele sempre brincava e se divertia, ao lembrar do meu passado como conselheiro, dizendo que eu o chamava de "Sarney da FEUFF". Eu sempre ficava vermelho de vergonha, tentava explicar que não foi isso, mas era em vão, aí que ele ria mais e caíamos na gargalhada.

Tive o privilégio de ver o Núcleo de Estudos e Pesquisa em Gestão e Políticas Públicas em Educação, o NUGEPPE, ser criado em 2010. Lembro de ajudá-lo nos trâmites de aprovação e no cadastro do grupo na plataforma do CNPq. Nesta época ele coordenava duas reuniões semanais, uma de orientação com seus mestrandos e a reunião do projeto sobre os impactos educacionais nos municípios do entorno do Complexo Petroquímico do Rio de Janeiro (COMPERJ), financiado pela Petrobras, em convênio com a UFF e ONU Habitat, em que eu atuava como bolsista. Sua ideia surgiu a partir da necessidade e vontade de criar um espaço para poder contribuir com uma 


\section{RevistAleph}

formação continuada mais sólida e uma oportunidade para o nosso aprofundamento teórico e dos ex-alunos que o procuravam para ingressar na pós-graduação.

O NUGEPPE só cresceu, sendo uma das referências nacionais na discussão sobre políticas educacionais. Jorge organizou vários livros, eventos e parcerias a partir do grupo. Tive a oportunidade de fazer minha primeira viagem internacional ao seu lado. E foi o NUGEPPE, sob sua coordenação, que me propiciou grandes experiências e produções no meio acadêmico.

Jorge também me acolheu no mestrado, minha orientadora solicitou o descredenciamento quando eu estava no $1^{\circ}$ semestre, e ele, de forma generosa, me estendeu a mão e foi determinante para que eu conseguisse defender minha dissertação, não desistiu de mim e me ajudou muito num processo formativo em que tive grandes dificuldades. Ele sempre dizia, "Leozinho, você precisa criar casca", "você está num momento da vida que precisa abrir portas", "você precisa de temperança Leo, temperança". Confesso que só mais tarde tudo isso fez todo o sentido para mim e me dou conta hoje de como suas palavras e sabedoria já fazem tanta falta.

Também foi determinante no incentivo e na revisão do projeto que elaborei para a seleção do doutorado. E na minha aprovação como professor assistente da Universidade do Estado do Amazonas (UEA).

Sempre foi alguém que plantou sementes, que distribuía alegria por onde passava e provocava através de seu exemplo e dedicação a ideia de que era preciso esperançar, mesmo em períodos de retrocessos e obscurantismos, como o tempo em que estamos vivendo.

Felizmente, como já mencionei, tive a oportunidade de agradecê-lo antes de sua partida. Já como professor aqui na UEA, na Floresta, como ele carinhosamente dizia que eu estava, em referência ao Amazonas, pude dizer que aqui tinha uma semente de Jorge Najjar, pois sempre carregarei em mim muito do exemplo de professor e ser humano comprometido com o outro que ele foi, obrigado por tudo amado mestre. Você deixou muitas saudades. 


\section{RevistAleph}

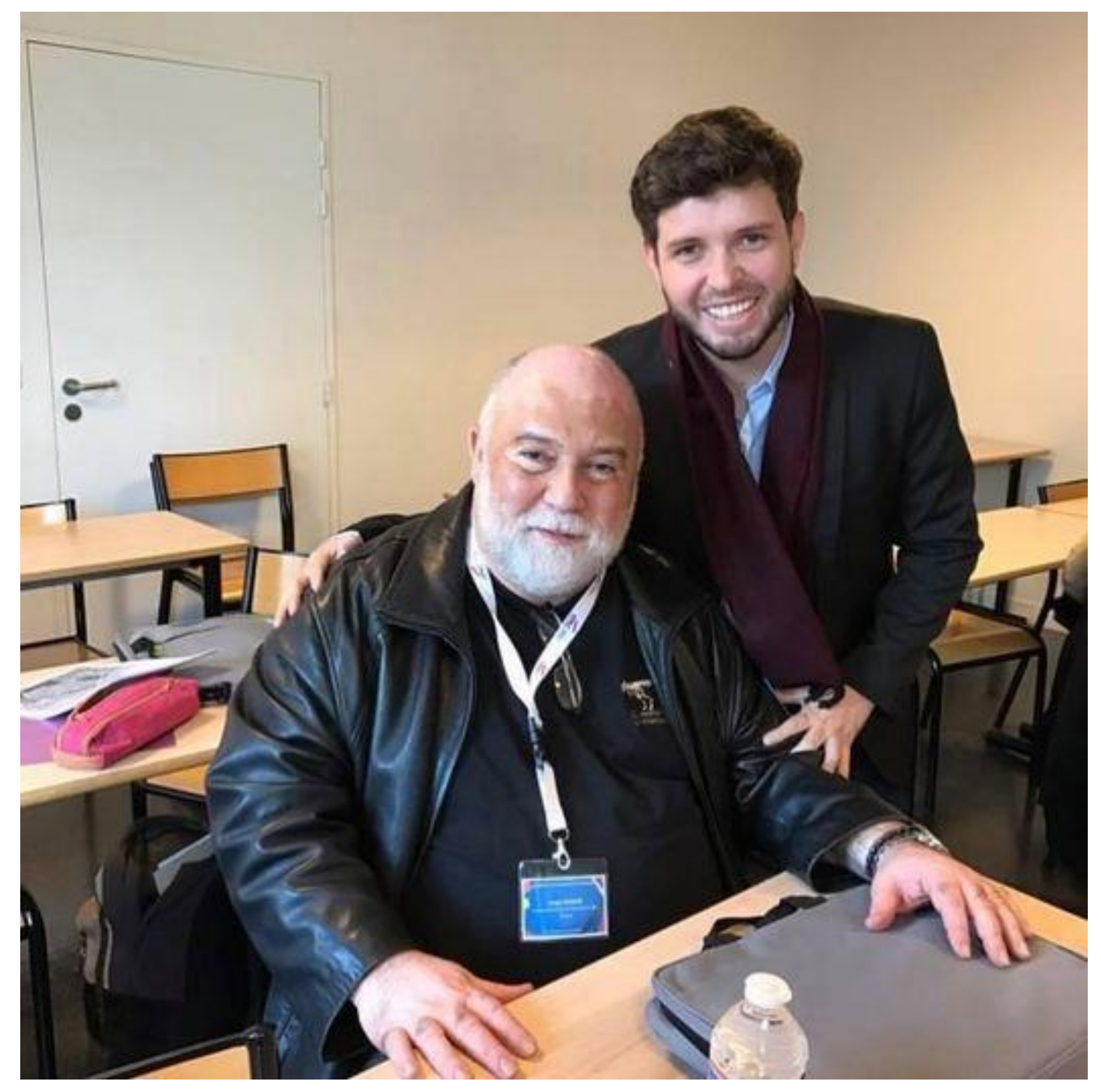

Fonte: Arquivo pessoal. 19/11/2016. Paris. 